\title{
Surface modification of stainless steels: green technology for corrosion protection $^{1}$
}

\author{
F. Mansfeld a, C.B. Breslin ${ }^{b}$, A. Pardo ${ }^{\text {}}$, F.J. Pérez ${ }^{\mathrm{c}}$ \\ ${ }^{a}$ Corrosion and Environmental Effects Laboratories, University of Southern California, \\ Department of Materials Science and Engineering, Los Angeles, CA 90089-0241, USA \\ ${ }^{b}$ Department of Chemistry, St. Patrick's College, Maynooth, Co. Kildare, Ireland \\ - Universidad Complutense de Madrid, Departamento de Ciencia de los Materiales, Facultad de Ciencias Quimicas, \\ 28040 Madrid, Spain
}

Received 23 April 1996; accepted 10 October 1996

\begin{abstract}
Many methods of corrosion protection rely on toxic chemicals such as hexavalent chromium $\left(\mathrm{Cr}^{6+}\right)$, which is the species responsible for protection in conversion coatings, anodizing baths and as a pigment in polymer coatings. Despite many attemps to replace $\mathrm{Cr}^{6+}$ and other harzardous chemicals in corrosion protection, very little progress has been made. Passive layers containing $\mathrm{Ce}$ and Mo have already been formed on materials such as A17075 and A12024, and their corrosion behaviour has been shown to improve by inhibition of both anodic and cathodic reaction. In this work the results of applying these coatings to SS304 and 316 will be presented. The layers were studied by electrochemical impedance spectroscopy (EIS), X-ray photo-electron spectroscopy (XPS), and the corrosion behaviour was followed by EIS and d.c. current methods. (O 1997 Elsevier Science S.A.
\end{abstract}

Keywords: Stainless steel; Corrosion protection; Impedance; Surface analysis

\section{Introduction}

Rare-earth metal salts, particularly those containing cerium, are effective corrosion inhibitors for iron $[1,2]$ and aluminum [2-5] in aggressive environments, and have been successfuly used in surface modification of various aluminum alloys [6-8] and stainless steels $[9,10]$, inhibiting both anodic and cathodic reactions. Similar results have been reported for stainless steels, but questions have been raised concerning the validity of some of these data [11].

Inhibition of anodic and cathodic reactions involved in the corrosion mechanism has been attributed to the formation and precipitation of cerium oxides or hydroxides over cathodic sites having a blocking effect [4-10]. The mechanism by which cerium forms a ceriumenriched hydroxide, particularly on stainless steel, is not clear. Indeed, the complexity of this process is evident, in that the valence state of cerium in the corresponding films varies between 3 and 4 , depending on the $\mathrm{pH}$ and

\footnotetext{
${ }^{1}$ Paper presented at 23 rd International Conference on metallurgical
} coatings and thin films, San Diego, CA, USA. the degree of aeration of the solution [5]. For aluminum alloys [6-8], adding molybdenum to cerium improves the corrosion behaviour significantly in some cases.

In this work, the electrochemical behaviour of SS304 and SS316L following various cerium and cerium/ molybdemum pre-treatment steps was studied in an effort to gain more information on the process by which cerium and molybdenum can modify the properties of the passive film formed on stainless steels. The coatings were analysed by EIS (electrochemical impedance spectroscopy) and XPS in order to identify the cerium species which play the main role in the enhacement of the passivation behaviour. The corrosion behaviour was followed by EIS and d.c. current methods.

\section{Experimental approach}

Cerium-containing layers were prepared by immersing the SS samples in the following solutions: $50 \mathrm{mM}$ $\mathrm{Ce}\left(\mathrm{NO}_{3}\right)_{3}, 10 \mathrm{mM} \mathrm{Ce}\left(\mathrm{NO}_{3}\right)_{3}, 10 \mathrm{mM} \mathrm{CeCl}$ or $40 \mathrm{mM}$ $\mathrm{Ce}_{3}\left(\mathrm{C}_{2} \mathrm{H}_{3} \mathrm{CO}\right)$ maintained at $95^{\circ} \mathrm{C}$ for periods ranging between 60 and $120 \mathrm{~min}$. Alternatively, trace amounts 
of cerium were deposited on the samples from cerium containing solutions at a cathodic current density of $10 \mu \mathrm{A} \mathrm{cm}^{-2}$ for a $10 \mathrm{~min}$ period. The cerium/ molybdenum-containing layers were obtained by immersing the samples in $0.25 \mathrm{M} \mathrm{Na}_{2} \mathrm{MoO}_{4}$ solution at $+500 \mathrm{mV}$ (SCE) for $50 \mathrm{~min}$ at $95^{\circ} \mathrm{C}$, followed by immersion in a $50 \mathrm{mM} \mathrm{Ce}\left(\mathrm{NO}_{3}\right)_{3}$ solution at $95^{\circ} \mathrm{C}$ for $60 \mathrm{~min}$. Additional tests involved immersing samples under the same conditions in $\mathrm{NaNO}_{3}, \mathrm{NaCl}$, $\mathrm{Na}\left(\mathrm{CH}_{3} \mathrm{CO}_{2}\right)$ for comparison.

The electrochemical tests were carried out using a PAR 273 Potentiostat. For the d.c. current methods the treated samples, used as working electrodes, were immersed in the test solution $(0.6 \mathrm{M} \mathrm{NaCl}$ and $0.1 \mathrm{M}$ $\mathrm{Na}_{2} \mathrm{SO}_{4}$ ) for $30 \mathrm{~min}$ and then polarized from the open circuit potential at a rate of $0.18 \mathrm{mV} \mathrm{s}^{-1}$ either in the anodic direction up to the pitting potential $E_{\text {pit }}$ or in the cathodic direction. The test solution was the same as the used by Lu and Ives $[9,10]$. Impedance spectra were collected in the same solution at $E_{\text {corr }}$ using a Solartron model 1250 FRA.

XPS was performed in an ESCA/XPS/AES Microtech MT500. The spectra were acquired at $15 \mathrm{kV}, 20 \mathrm{~mA}$ and at $P<10^{-8}$ mbar. The samples were sputtered in $\mathrm{Ar}$ atmosphere for $3 \mathrm{~min}$ before data acquisition in order to remove surface contaminants.

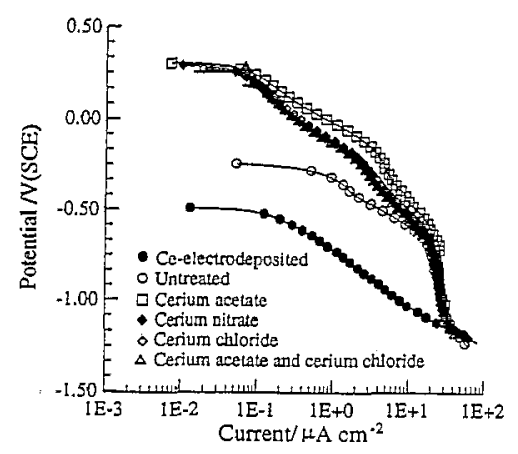

Fig. 1. Cathodic polarization curves for type AISI 316L stainless steel in $0.6 \mathrm{M} \mathrm{NaCl}+0.1 \mathrm{M} \mathrm{Na}_{2} \mathrm{SO}_{4}$.

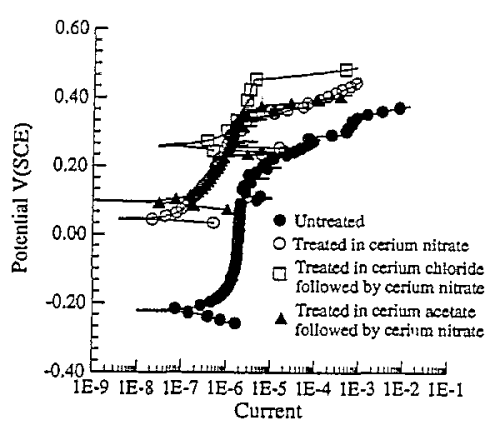

Fig. 2. Anodic polarization curves for type AIST $316 \mathrm{~L}$ stainless steel in $0.6 \mathrm{M} \mathrm{NaCl}+0.1 \mathrm{M} \mathrm{Na}_{2} \mathrm{SO}_{4}$.
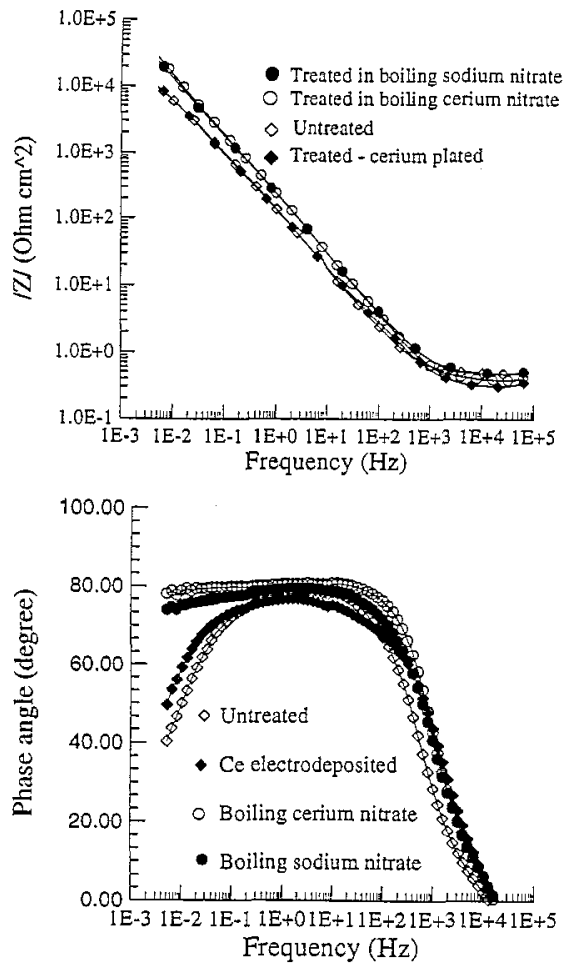

Fig. 3. Bode-plot curves for type AISI $316 \mathrm{~L}$ stainless steel in $0.6 \mathrm{M}$ $\mathrm{NaCl}+0.1 \mathrm{M} \mathrm{Na}_{2} \mathrm{SO}_{4}$.

\section{Results and discussion}

Fig. 1 shows the cathodic polarization characteristics of SS316L following various cerium pre-treatment steps. All immersion treatments were carried out at 90$95^{\circ} \mathrm{C}$ for $1 \mathrm{~h}$. The pre-treatment step designated as $\mathrm{Ce}\left(\mathrm{CH}_{3} \mathrm{CO}_{2}\right)_{3}$ and $\mathrm{CeCl}_{3}$ involved immersing the electrodes in the $\mathrm{Ce}\left(\mathrm{CH}_{3} \mathrm{CO}_{2}\right)_{3}$ solution for $1 \mathrm{~h}$ and then in the $\mathrm{CeCl}_{3}$ solution for one additional hour at approximately $92{ }^{\circ} \mathrm{C}$. Regardless of the nature of the cerium salt, no changes in the rate of the cathodic reduction reaction could be observed, in contrast with the results of $\mathrm{Lu}$ and Ives [10], who reported a drastic reduction of the rate of oxygen reduction following immersion in hot $\mathrm{Ce}\left(\mathrm{NO}_{3}\right)_{3}$. The increase of the corrosion potential $E_{\text {corr }}$ is due mainly to a decrease of the passive current density, suggesting that treatment in cerium solutions did not affect the rate of the cathodic reaction, but reduced the rate of the passive film dissolution. Similar results were obtained for SS304.

Variations in the cerium concentrations between 0.01 and $0.1 \mathrm{~mol} \mathrm{dm}^{-3}$, variations in the $\mathrm{pH}$ of the cerium solution between 2.0 and 4.5 , or variations in the purity of the cerium salts had little effect on the cathodic polarization characteristics. However, a significant reduction in the oxygen reduction current could be observed following the electrodeposition of small amounts of cerium onto the electrode surface (Fig. 1). 
Thus, it appears that efficient formation of cerium hydroxide/oxide did not occur on immersing electrodes at elevated temperatures in cerium solutions. It was possible to observe a yellow colored film indicative of cerium in the +4 oxidation state on the surface of the stainless steel following a $24-\mathrm{h}$ immersion period in the $\mathrm{Ce}\left(\mathrm{NO}_{3}\right)_{3}$ solution at room temperature. However, this film was only loosely adherent and became detached from the surface during the experiment. The reasons for the discrepancy between these results and those reported by Lu and Ives [10] are not clear at the present.

The anodic polarization behaviour of SS304 following various pre-treatment steps is shown in Fig. 2. Treatment of SS304 in cerium-salt solutions gave rise to an increase in the pitting potential $E_{\mathrm{pit}}$, with the greatest increase resulting from immersion in $\mathrm{CeCl}_{3}$ at $90-95^{\circ} \mathrm{C}$ for 30 min followed by immersion in $\mathrm{Ce}\left(\mathrm{NO}_{3}\right)_{3}$ at $90-95^{\circ} \mathrm{C}$ for an additional $60 \mathrm{~min}$. Similar results were obtained after treatment in $\mathrm{NaCl}$ and $\mathrm{NaNO}_{3}$ solutions under otherwise identical conditions. The enhanced resistance to the onset of pitting could be due to the dissolution of surface $\mathrm{MnS}$ inclusions during immersion in the chloride-containing solution and possibly chromium enrichement of the passive film during treatment in the sodium nitrate solution which is highly oxidizing. The presence of cerium in the solution seemed to have only a minor effect on $E_{\text {pit }}$.

The impedance spectra in Fig. 3 exhibit essentially capacitive behaviour for untreated samples which had been treated by boiling $\mathrm{Ce}\left(\mathrm{NO}_{3}\right)_{3}$ or $\mathrm{NaNO}_{3}$, or which contained electrodeposited cerium compounds. However, it is obvious that the impedance at the lowest frequencies was increased, and the capacitance $C$ decreased for the samples treated in in hot nitrate solutions. No significant changes in the polarization resistance $R_{\mathrm{p}}$ were observed for the two other samples. $R_{\mathrm{p}}$ for the untreated and Ce electrodeposited samples was between 0.2 and $0.3 \Omega \mathrm{M} \mathrm{cm}^{-2}$, while it increased to values between 5 and $7 \Omega \mathrm{M} \mathrm{cm}^{-2}$ for the samples treated by boiling in $\mathrm{Ce}\left(\mathrm{NO}_{3}\right)_{3}$ or $\mathrm{NaNO}_{3}$. The impedance spectra in Fig. 3 suggest that treatment in hot nitrate solutions increased the thickness in the passive film and decreased its dissolution rates as compared to the untreated sample. These improvements of

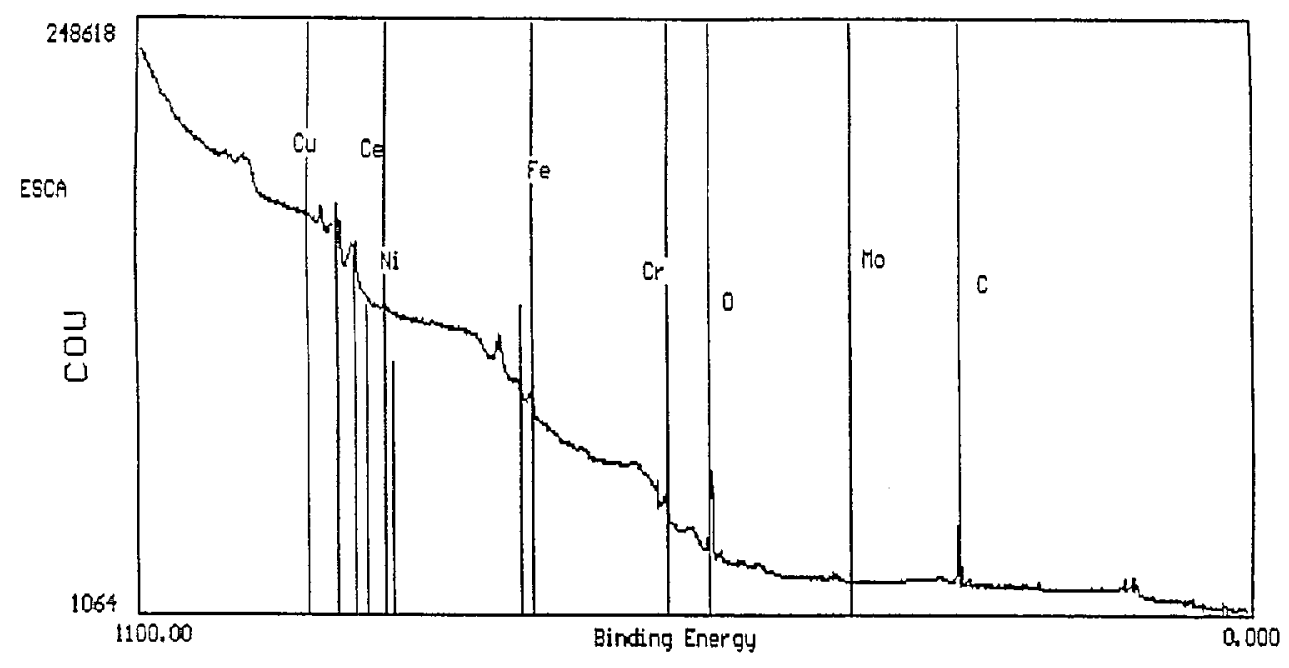

Fig. 4. XPS spectrum for AISI 316L stainless steel treated with cerium acetate (M1).

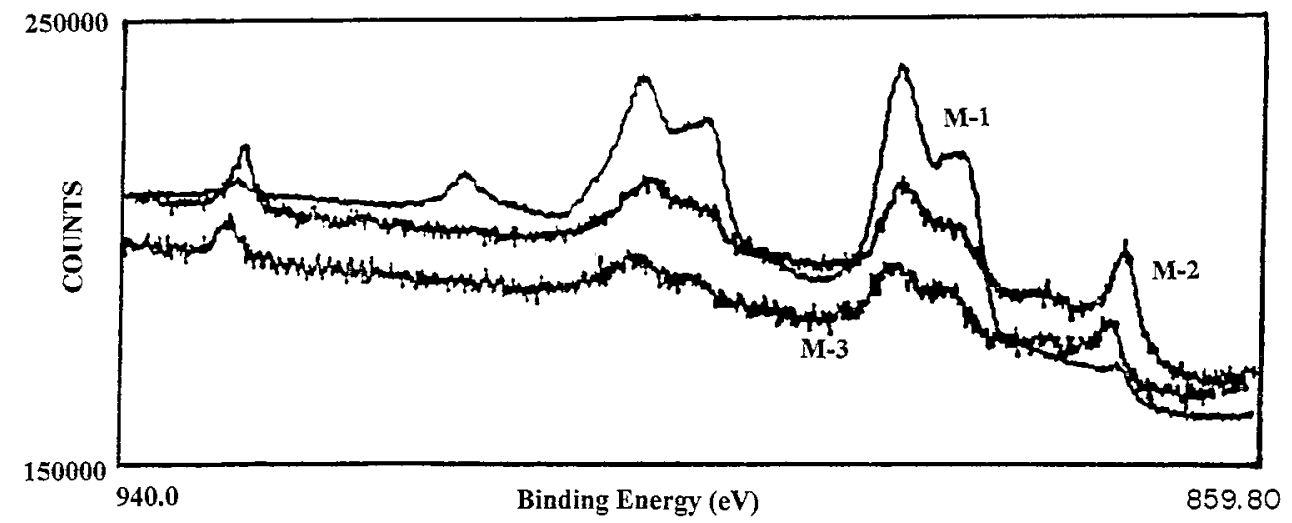

Fig. 5. Cerium energy window for the AISI 316L stainless steel treated with three different Ce processes (M1, M2 and M3). 


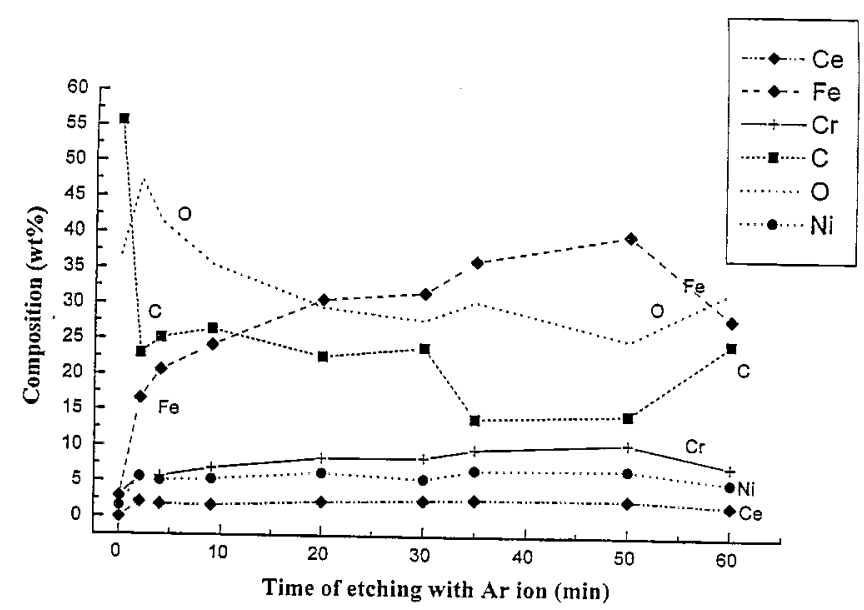

Fig. 6. Depth profile of elements in passive layer of AISI $316 \mathrm{~L}$ stainless steel treated with M1 process.

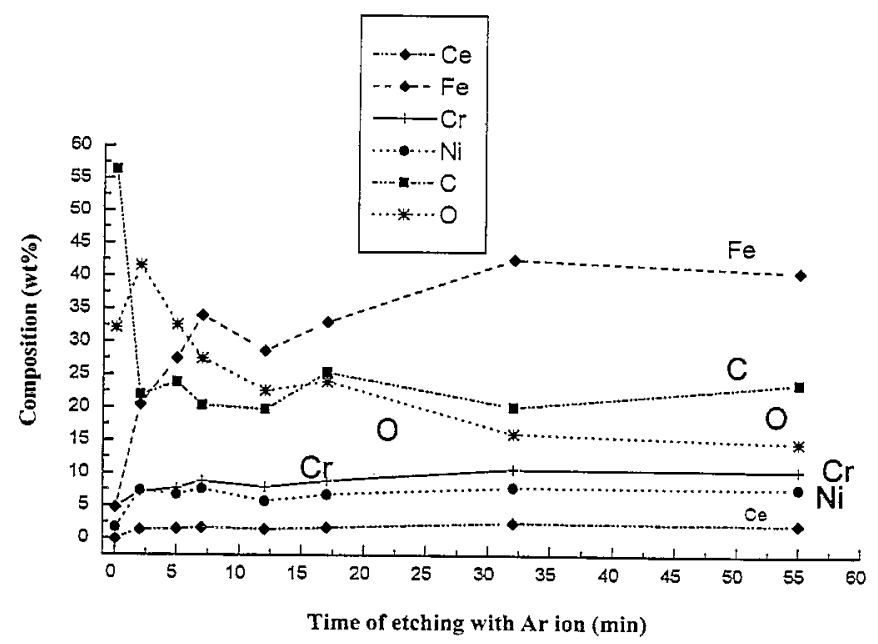

Fig. 7. Depth profile of elements in passive layer of AISI 316L stainless steel treated with M3 process.

passive film properties can explain the observed increase of $E_{\text {pit }}$ (Fig. 2). Since nitrate solutions are highly oxidizing, it is also possible that the chromium content in the passive film was increased.

Fig. 4 shows the XPS spectrum corresponding to SS316L treated in $\mathrm{Ce}\left(\mathrm{CH}_{3} \mathrm{CO}_{2}\right)_{3}$ at $95^{\circ} \mathrm{C}$ for $60 \mathrm{~min}$ (M1). For polarization in $0.25 \mathrm{M} \mathrm{Na}_{2} \mathrm{MoO}_{4}$ solution at $+50 \mathrm{mV}$ (SCE) for $50 \mathrm{~min}$ at $95^{\circ} \mathrm{C}$, followed by immersion in a $50 \mathrm{mM} \mathrm{Ce}\left(\mathrm{NO}_{3}\right)_{3}$ solution at $95^{\circ} \mathrm{C}$ for $60 \mathrm{~min}$ (M2), and immersion in $50 \mathrm{mM} \mathrm{CeCl} 3$ for $30 \mathrm{~min}$ followed by inmersion in $50 \mathrm{mM} \mathrm{Ce}\left(\mathrm{NO}_{3}\right)_{3}$ at $95^{\circ} \mathrm{C}$ for $60 \mathrm{~min}$ (M3), respectively, all analyses resulted in similar spectra. Table 1 shows the results of surface analysis for the three surface treatments applied on SS316L.

Fig. 5 contains the portion of the spectra where cerium peaks appear $(860-940 \mathrm{eV})$ for the three samples. Ce (binding energy $3 \mathrm{~d}_{5 / 2}=884 \mathrm{eV}$ ), $\quad \mathrm{CeO}_{2}$ (binding energy $3 \mathrm{~d}_{5 / 2}=882 \mathrm{eV}$ ), $\quad \mathrm{CeCu}_{2} \mathrm{Si}_{2}$ (binding energy $3 \mathrm{~d}_{5 / 2}=883.7 \mathrm{eV}$ ) and $\mathrm{CeH}_{3}$ (binding energy $3 \mathrm{~d}_{5 / 2}=$ $886 \mathrm{eV}$ ) peaks were assigned to the spectra. The element
Table 1

XPS surface analysis of AISI 316L steel treated with cerium processes

\begin{tabular}{lrrrrrr}
\hline Sample & $\mathrm{Fe}$ & $\mathrm{Cr}$ & $\mathrm{Ni}$ & $\mathrm{Ce}$ & $\mathrm{C}$ & $\mathrm{O}$ \\
\hline M1 & 11.8 & 7.2 & 4.3 & 0.8 & 21.2 & 51.6 \\
M2 & 8.1 & 10.6 & 1.8 & 0.4 & 15.1 & 64.0 \\
M3 & 15.3 & 13.2 & 5.9 & 0.6 & 17.4 & 47.6 \\
\hline
\end{tabular}

profiles in the passive layer of the modified AISI 316L steel have been determined with XPS with an Ar ion gun after $60 \mathrm{~min}$, corresponding to removal of $20 \mathrm{~A}$, when the thickness of the passive layer was about $30 \mathrm{~A}$. The cerium concentration in the passive layer is similar in all cases, $0.8 \%$ for M1 treatment (Fig. 6), 0.4\% for M2 treatment, and $0.6 \%$ for M3 treatment (Fig. 7).

Further studies are being carried out in order to elucidate the role of cerium salts in corrosion protection of stainless steels and aluminum alloys [11]. 


\section{Acknowledgement}

The authors wish to express their gratitude to the NATO Scientific Affairs Division for financial support of this work.

\section{References}

[1] B.P.F. Goldie and J.J. McCarroll, Australian Patent AU-32947/ 84 (1984).
[2] H.S. Isaacs, A.J. Davenport and A. Shipley, J. Electrochem. Soc., 138 (1991) 138.

[3] R.B.W. Hilton, D.R. Arnott and N.E. Ryan, Metals Forum, 7 (1984) 211.

[4] R.B.W. Hilton, J. Alloys Compounds, 180 (1992) 15.

[5] A.J. Aldekiewicz, H.S. Isaacs and A.J. Davenport, J. Electrochem. Soc., 142 (1995) 3342.

[6] F. Mansfeld and Y. Wang, Br. Corros. J., 29 (1994) 194.

[7] F. Mansfeld and Y. Wang, Mater. Sc. Eng., A198 (1995) 51.

[8] F. Mansfeld, Y. Wang and H. Shih, J. Electrochem. Soc., 138 (1991) L74.

[9] Y.C. Lu and M.B. Ives, Corros. Sci., 34 (1993) 1773.

[10] Y.C. Lu and M.B. Ives, Corros. Sci., 37 (1995) 145.

[11] F. Mansfeld, C. Breslin, C. Chen, F.J. Pérez, A. Pardo, C. Merino, M.P. Hierro and E. Otero, NATO Report, November 1996. 